\title{
Editorial
}

\section{Oxidative stress may be a common mechanism linking major depression and osteoporosis}

\section{Introduction}

Chronic conditions constitute the bulk of the disease load, particularly in Western societies. The prevalence and consequences of such conditions are becoming better appreciated, although the intricacies of their pathogenesis and interrelationships are largely not definitively determined. Major depressive disorder and osteoporosis are two pertinent examples of increasingly prevalent disorders that appear to be related. Several epidemiological studies have reported diminished bone mineral density among depressed men and women compared with controls (1-10), dysregulation of bone turnover $(3,5,8)$ and increased risk for fracture (11-13). Data from animal models show that stress-induced depression leads to altered rates of bone remodelling (14) and loss of trabecular bone volume, trabecular number and connectivity (15). Although these studies are heterogeneous in design, they reveal a consistent association between depression and indices of osteoporosis. The nature of this association remains to be clarified, but a number of pathophysiological pathways are potential mediating mechanisms. Among these, oxidative stress stands out as a plausible candidate, given the fundamentality of oxidation physiology, and the newly emerging evidence for an intrinsic role of oxidative stress in both major depression and osteoporosis.

\section{Oxidative stress}

At higher concentrations, free radicals and nonradical reactive species are hazardous for living organisms and damage major cellular constituents. At lower concentrations, however, nitric oxide and reactive oxygen species (ROS, including superoxide, singlet oxygen, hydrogen peroxide and the highly reactive hydroxyl radical) play important roles as regulatory mediators in signalling processes $(16,17)$. Many ROS-mediated responses protect cells against exposure to oxidants and re-establish reduction/ oxidation (redox) homeostasis. Excess ROS disrupt cellular redox status, leading to a net oxidative overbalance ('oxidative stress'), which causes cellular dysfunction, and has been implicated in the pathogenesis of disease including cancer (18), diabetes mellitus (19), atherosclerosis (20) and rheumatoid arthritis (21). Progressive changes in free-radical-mediated regulatory processes may also play a role in the aetiology of both depression and osteoporosis and may, in part, mediate their association.

\section{Oxidative stress and depression}

Altered levels of antioxidative enzymes (22-25) and the lipid peroxidation product malondialdehyde (22-24) have been reported in major depression, especially in cases with melancholic features (22). Normalisation of oxidative stress markers with antidepressant treatment has been demonstrated $(22,23,25)$, and a positive correlation was reported between oxidative stress index values and severity of depression (26). These findings strengthen the hypothesis that oxidative stress is inherent in active depressive illness processes.

Further support for the relevance of oxidative stress behind depressive illness pathogenesis can be found in pharmacology studies. Established antidepressants have been shown to possess antioxidant properties in cellular and animal studies. For instance, the monoamine oxidase (MAO) inhibitor phenelzine has been observed using in vitro cell studies to modulate oxidative stress pathways via several mechanisms that included hydrogen peroxide scavenging and the prevention of MPP+-induced decrease in mitochondrial membrane potential, cytochrome $c$ release, formation of ROS and depletion of 
glutathione (27). The reversible inhibitor of MAO-A, moclobemide, has been shown to significantly increase the survival of rat neuronal-astroglial cultures using in vitro models of brain ischaemia, with decreased free radical formation through MAO-A inhibition being the hypothesised mechanism (28). Venlafaxine reduced levels of oxidative stress in a rat model of depression (induced by chronic mild stress), as indexed by increased glutathione peroxidase activity and glutathione and vitamin $\mathrm{C}$ levels and by lower nitric oxide levels and lipid peroxidation in the brain (29). Both venlafaxine and fluoxetine have been shown to modulate antioxidant proteins, among others, in a proteomic study (30).

\section{Oxidative stress and osteoporosis}

Bone loss occurs as a result of imbalances in bone remodelling, whereby osteoclastic bone resorption exceeds osteoblastic bone formation (31). Adult ageing is accompanied by bone loss (32), decreases in plasma antioxidant enzymes (33) and reduced antioxidant intakes in the diet (34). The rate of bone remodelling and negative bone balance increases after menopause in women, accelerating bone loss and trabecular and cortical thinning, and increasing bone porosity and fragility (35).

There is compelling in vitro and in vivo evidence to suggest that oxidative stress is involved in bone cell biology. Antioxidant defences were found to fall in the bone marrow of female rats after ovariectomy, and the response was rapidly normalised by exogenous 17- $\beta$ oestradiol and prevented by the antioxidants $N$-acetylcysteine (NAC) and ascorbate (36). By contrast L-buthionine-(SR)sulphoximine (BSO), a specific inhibitor of glutathione, the major intracellular antioxidant, caused substantial bone loss. Furthermore, depletion of antioxidants by BSO, like ovariectomy, caused bone loss through tumour necrosis factor- $\alpha$ (TNF- $\alpha$ ) signalling, and in ovariectomised mice treated with soluble TNF- $\alpha$ receptors, antioxidant defences in bone remained low, despite inhibition of bone loss (37). The authors concluded that low levels of antioxidants in bone following ovariectomy were the cause of increased bone resorption.

The antioxidant vitamins are vitamins $\mathrm{C}$ and $\mathrm{E}$ and the $\beta$-carotene form of vitamin A. Guinea pig studies have shown that low vitamin $\mathrm{C}$ intake in growing animals is associated with high rates of bone turnover (38). Epidemiological studies have found a positive association between dietary vitamin $\mathrm{C}$ intake and bone mineral density in postmenopausal women (39-41), and low dietary intakes of vitamins $\mathrm{C}$ and $\mathrm{E}$ have been linked to an increased risk of hip fracture in smokers (42). Diminished dietary and endogenous antioxidants have been reported among elderly osteoporotic women compared with age-matched controls (43), with differences significant for dietary vitamins $\mathrm{A}, \mathrm{C}$ and $\mathrm{E}$, and for endogenous molecules with scavenging activity (specifically uric acid, superoxide dismutase and glutathione peroxidase). Antioxidant vitamin supplements have been associated with reduced rates of bone resorption in non-smoking postmenopausal women (44), and a recently reported randomised controlled trial showed progressively reduced bone resorption in early postmenopausal women treated with the potent orally administered antioxidant, NAC (45). Vitamin intake may, however, be associated with other risk factors.

It should be noted that excess dietary retinol intake has been identified as a risk factor for hip fracture and associated with accelerated bone loss $(46,47)$. It has been suggested that serum concentrations of vitamin $\mathrm{A}$ at both ends of the spectrum (high and low) increase the risk of hip fracture (48). The role of retinol, in addition to other forms of vitamin $\mathrm{A}$ (including $\beta$-carotene), remains unclear. However, taken in aggregate, the findings suggest a positive role for antioxidants in protecting against bone loss.

\section{Oxidative stress connecting depression and osteoporosis}

An initial hypothesis for the association between osteoporosis and depression related to hypercortisolaemia, which has been observed in major depression and is known to be detrimental to the skeleton (49). However, this seems more suitable in explaining a unidirectional relationship and is unlikely to be the sole mechanism of the association between these two conditions, given the complexities of their aetiologies and pathogenic processes.

An advantage of examining pathogenesis from the oxidative stress perspective is the explanatory power afforded by its fundamental placement in the hierarchical aetiopathogenic framework, which extends from gross extrinsic influences to basic molecular biology. Hence, regardless of the initial insults responsible for the illness, oxidative stress may be a common trunk pathogenic pathway, which may become a self-perpetuating process that progressively induces disease states in susceptible individuals. Because of this basic role and its ubiquitous involvement in all bodily systems, oxidative stress stands out as a prime candidate mediator in the pathophysiology of comorbid diseases. As there is already evidence that 


\section{Editorial}

establishes an active role for oxidative stress in the development of both major depression and osteoporosis, the extension of this role to a mediating one seems most plausible on both theoretical and empirical grounds.

It would of course be simplistic and unconvincing to assert that oxidative stress is the only mediating mechanism, when most diseases including major depression and osteoporosis involve multiple pathological paths. The capacity for the oxidative stress hypothesis to incorporate the action of other mechanisms through the confluence of oxidative pathways with other biopathways is one of its strengths. Immunological pathways provide a useful example for this discussion. For major depression and osteoporosis, each has individually accrued literature on immunological changes that seem intrinsically related to the disease process. In major depression, these include the acute-phase response, comprising raised haptoglobin, interleukin (IL)-6, complement factors and C-reactive protein (50-53), impaired lymphocyte proliferative response to mitogens and reduced lymphocyte phagocytosis (54). Elevated serum high-sensitivity C-reactive protein (hsCRP) has been reported in a large sample of women with osteopenia or osteoporosis and has been positively correlated with serum alkaline phosphatase levels, indicating states of accelerated bone turnover (55). Serum hsCRP has recently been identified as a prognostic marker of fracture (56-58). Various anti-inflammatory and proinflammatory cytokines including IL-1, IL-6, TNF- $\alpha$ and $-\beta$, transforming growth factor- $\alpha$ and $-\beta$, granulocyte-monocyte colony-stimulation factor, monocyte-macrophagestimulating factor and prostaglandin $\mathrm{E}_{2}$ are understood to be important in the normal bone remodelling process $(59,60)$. There is abundant evidence that cytokines and the inflammatory response are closely linked to oxidative stress states (61-63), and this might provide a further nexus in the mediating role of oxidative stress for depression and osteoporosis.

Although oxidative stress is unlikely to be the sole mediator between major depression and osteoporosis, it offers an attractive hypothesis for further study for several reasons. Its omnipresent role in human physiology and its applicability to diverse, if not universal, pathological processes suggest that it may be comparatively dominant among different biological pathogenic mechanisms. Furthermore, it may have important practical implications in that antioxidants may have undiscovered preventive and therapeutic values. The oxidative stress hypothesis raises the possibility that sustaining antioxidant defences during ageing may be protective against these diseases. Antioxidant defences may be sustained through antioxidant intake, body habitus and lifestyle, and this field of research warrants further investigation. Nutritional epidemiology has already suggested that dietary antioxidants are crucially involved in the prevention of certain degenerative diseases, but at this time, the scientific data do not justify the use of antioxidants for risk reduction of depression or osteoporosis. We anticipate data for developing evidence-based recommendations for new methods of intervention using available tolerable, safe and affordable antioxidant approaches.

\section{Conclusions}

We have postulated and explored the concept that development of major depression and deterioration of the skeleton are both influenced by increased oxidative stress levels. Indeed, markers of oxidative stress within depression and osteoporosis may play a vital role in disease expression and suggest a mediating link between these disorders. In addition to pathological understanding, this hypothesis introduces opportunities to investigate novel treatment approaches, which may be of benefit to the outcomes of debilitating chronic diseases.

\section{Julie A. Pasco ${ }^{I}$, Geoffrey C. Nicholson ${ }^{1}$,} Felicity $\mathrm{Ng}^{l}$, Margaret J. Henry ${ }^{l}$, Lana J. Williams ${ }^{l}$, Mark A. Kotowicz ${ }^{1}$, Jason M. Hodge ${ }^{I}$, Seetal Dodd ${ }^{l}$, Flavio Kapczinski ${ }^{2}$, Clarissa S. Gama ${ }^{2,3}$, Michael Berk ${ }^{1,4,5}$

${ }^{I}$ Department of Clinical and Biomedical Sciences: Barwon Health, The University of Melbourne, Geelong, Australia

${ }^{2}$ Programa de Pós-Graduação em Medicina: Psiquiatria, Universidade Federal do Rio Grande do Sul, Porto Alegre, RS, Brazil ${ }^{3}$ Conselho Nacional de Desenvolvimento Cientifico e Tecnologico, Brazil

${ }^{4}$ Orygen Research Centre, Parkville, Australia ${ }^{5}$ Mental Health Research Institute, Parkville, Australia

\section{References}

1. Schweiger U, Deuschle M, Korner A et al. Low lumbar bone mineral density in patients with major depression. Am J Psychiatry 1994;151:1691-1693.

2. Halbreich U, Rojansky N, Palter $S$ et al. Decreased bone mineral density in medicated psychiatric patients. Psychosom Med 1995;57:485-491. 
3. Michelson D, Stratakis C, Hill L et al. Bone mineral density in women with depression. $\mathrm{N}$ Engl $\mathrm{J}$ Med 1996;335:1176-1181.

4. Cizza G, Ravn P, Chrousos GP, Gold PW. Depression: a major, unrecognized risk factor for osteoporosis? Trends Endocrinol Metab 2001;12:198-203.

5. Yazici KM, Akinci A, Sutcu A, Ozcakar L. Bone mineral density in premenopausal women with major depressive disorder. Psychiatry Res 2003;117:271-275.

6. Jacka FN, Pasco JA, Henry MJ et al. Depression and bone mineral density in a community sample of perimenopausal women: Geelong Osteoporosis Study. Menopause 2005;12:88-91.

7. Wong Sy, Lau EM, Lynn H et al. Depression and bone mineral density: is there a relationship in elderly Asian men? Results from Mr. Os (Hong Kong). Osteoporos Int 2005;16:610-615.

8. Kahl KG, Greggersen W, Rudolf $\mathrm{S}$ et al. Bone mineral density, bone turnover, and osteoprotegerin in depressed women with and without borderline personality disorder. Psychosom Med 2006;68:669-674.

9. Altindag O, Altindag A, Asoglu M, Gunes M, Soran N, Deveci Z. Relation of cortisol levels and bone mineral density among premenopausal women with major depression. Int J Clin Pract 2007;61:416-420.

10. Jacka FN, Pasco JA, Henry MJ et al. Depression and bone mineral density in a community sample of men: Geelong Osteoporosis Study. J Mens Health Gend 2007; 4:292-297.

11. Whooley MA, Kip Ke, Cauley JA, Ensrud Ke, Nevitt MC, BRowner WS. Depression, falls, and risk of fracture in older women. Study of Osteoporotic Fractures Research Group. Arch Intern Med 1999;159:484-490.

12. Forsen L, Meyer He, Sogand AJ, Naess S, Schei B, EDNA TH. Mental distress and risk of hip fracture. Do broken hearts lead to broken bones? J Epidemiol Community Health 1999;53:343-347.

13. Mussolino ME. Depression and hip fracture risk: the NHANES I epidemiologic follow-up study. Public Health Rep 2005;120:71-75.

14. Patterson-Buckendahl PE, Grindeland RE, Shakes DC, Morey-Holton ER, Cann CE. Circulating osteocalcin in rats is inversely responsive to changes in corticosterone. Am J Physiol 1988;254:R828-R833.

15. Yirmiya R, Goshen I, Bajayo A et al. Depression induces bone loss through stimulation of the sympathetic nervous system. Proc Natl Acad Sci U S A 2006;103: 16876-16881.

16. Droge W. Free radicals in the physiological control of cell function. Physiol Rev 2002;82:47-95.

17. HAdDAD JJ. Antioxidant and prooxidant mechanisms in the regulation of redox $(\mathrm{y})$-sensitive transcription factors. Cell Signal 2002;14:879-897.

18. Dreher D, JunOd AF. Role of oxygen free radicals in cancer development. Eur J Cancer 1996;32A:30-38.

19. WolfF SP. Diabetes mellitus and free radicals. Free radicals, transition metals and oxidative stress in the aetiology of diabetes mellitus and complications. Br Med Bull 1993;49:642-652.

20. Alexander RW. Theodore Cooper Memorial Lecture. Hypertension and the pathogenesis of atherosclerosis. Oxidative stress and the mediation of arterial inflammatory response: a new perspective. Hypertension 1995;25: 155-161.

21. Mapp PI, Grootveld MC, Blake DR. Hypoxia, oxidative stress and rheumatoid arthritis. Br Med Bull 1995; 51:419-436.
22. Bilici M, Efe H, Koroglu MA, Uydu HA, Bekaroglu M, Deger O. Antioxidative enzyme activities and lipid peroxidation in major depression: alterations by antidepressant treatments. J Affect Disord 2001;64:43-51.

23. Khanzode SD, Dakhale GN, Khanzode SS, Saoji A, Palasodkar R. Oxidative damage and major depression: the potential antioxidant action of selective serotonin reuptake inhibitors. Redox Rep 2003;8:365-370.

24. Sarandol A, Sarandol E, Eker SS, Erdinc S, VatansEVER E, KIRLI S. Major depressive disorder is accompanied with oxidative stress: short-term antidepressant treatment does not alter oxidative-antioxidative systems. Hum Psychopharmacol 2007;22:67-73.

25. Herken H, Gurel A, Selek $S$ et al. Adenosine deaminase, nitric oxide, superoxide dismutase, and xanthine oxidase in patients with major depression: impact of antidepressant treatment. Arch Med Res 2007;38:247-252.

26. Yanik M, Erel O, Katoi M. The relationship between potency of oxidative stress and severity of depression. Acta Neuropsychiatrica 2004;16:200-203.

27. LeE CS, HAN ES, LeE WB. Antioxidant effect of phenelzine on MPP+-induced cell viability loss in differentiated PC12 cells. Neurochem Res 2003;28:1833-1841.

28. Verleye M, Steinschneider R, Bernard FX, Gillardin JM. Moclobemide attenuates anoxia and glutamateinduced neuronal damage in vitro independently of interaction with glutamate receptor subtypes. Brain Res 2007; 1138:30-38.

29. Eren I, Naziroglu M, Demirdas A et al. Venlafaxine modulates depression-induced oxidative stress in brain and medulla of rat. Neurochem Res 2007;32:497-505.

30. Khawaja X, Xu J, Liang JJ, Barrett JE. Proteomic analysis of protein changes developing in rat hippocampus after chronic antidepressant treatment: implications for depressive disorders and future therapies. J Neurosci Res 2004;75:451-460.

31. Riggs BL, Khosla S, Melton LJ III. Sex steroids and the construction and conservation of the adult skeleton. Endocr Rev 2002;23:279-302.

32. Henry MJ, Pasco JA, Nicholson GC, Seeman E, Kотошісz MA. Prevalence of osteoporosis in Australian women: Geelong Osteoporosis Study. J Clin Densitom 2000;3:261-268.

33. Ceballos-Picot i, Trivier JM, Nicole A, Sinet PM, TheVenin M. Age-correlated modifications of copper-zinc superoxide dismutase and glutathione-related enzyme activities in human erythrocytes. Clin Chem 1992;38:66-70.

34. Mertz W. The role of trace elements in the aging process. Prog Clin Biol Res 1990;326:229-240.

35. Mosekilde L. Consequences of the remodelling process for vertebral trabecular bone structure: a scanning electron microscopy study (uncoupling of unloaded structures). Bone Miner 1990;10:13-35.

36. Lean JM, Davies JT, Fuller K et al. A crucial role for thiol antioxidants in estrogen-deficiency bone loss. J Clin Invest 2003;112:915-923.

37. Lean J, Kirstein B, Urry Z, Chambers T, Fuller K. Thioredoxin-1 mediates osteoclast stimulation by reactive oxygen species. Biochem Biophys Res Commun 2004;321: $845-850$.

38. Kipp DE, Grey CE, McElvain ME, Kimmel DB, Robinson RG, LuKert BP. Long-term low ascorbic acid intake reduces bone mass in guinea pigs. J Nutr 1996;126: 2044-2049.

39. Hall SL, Greendale GA. The relation of dietary vitamin $\mathrm{C}$ intake to bone mineral density: results from the PEPI study. Calcif Tissue Int 1998;63:183-189. 


\section{Editorial}

40. Leveille SG, LaCroix AZ, Koepsell Td, Beresford SA, Van Belle G, Buchner DM. Dietary vitamin C and bone mineral density in postmenopausal women in Washington State, USA. J Epidemiol Community Health 1997;51:479-485.

41. Wang MC, Luz Villa M, Marcus R, Kelsey JL. Associations of vitamin $\mathrm{C}$, calcium and protein with bone mass in postmenopausal Mexican American women. Osteoporos Int 1997;7:533-538.

42. Melhus H, Michaelsson K, Holmberg L, Wolk A, LuUnghall S. Smoking, antioxidant vitamins, and the risk of hip fracture. J Bone Miner Res 1999;14:129-135.

43. Maggio D, Barabani M, Pierandrei M et al. Marked decrease in plasma antioxidants in aged osteoporotic women: results of a cross-sectional study. J Clin Endocrinol Metab 2003;88:1523-1527.

44. Pasco JA, Henry MJ, Wilkinson LK, Nicholson GC, Schneider HG, Kotowicz MA. Antioxidant vitamin supplements and markers of bone turnover in a community sample of nonsmoking women. $\mathbf{J}$ Womens Health (Larchmt) 2006;15:295-300.

45. Sanders KM, Kotowicz MA, Nicholson GC. The potential role of the antioxidant $\mathrm{N}$-acetylcysteine in slowing bone resorption in early post-menopausal women: a pilot study. Transl Res 2007;150:215.

46. Melhus H, Michaelsson K, Kindmark A et al. Excessive dietary intake of vitamin $\mathrm{A}$ is associated with reduced bone mineral density and increased risk for hip fracture. Ann Intern Med 1998;129:770-778.

47. Feskanich D, Singh V, Willett WC, Colditz GA. Vitamin A intake and hip fractures among postmenopausal women. JAMA 2002;287:47-54.

48. Opotowsky AR, BiLEZIKIAN JP. NHANES I Follow-Up Study. Serum vitamin A concentration and the risk of hip fracture among women 50 to 74 years old in the United States: a prospective analysis of the NHANES I follow-up study. Am J Med 2004;117:169-174.

49. Seeman E, Wahner HW, Offord KP, Kumar R, Johnson WJ, Riggs BL. Differential effects of endocrine dysfunction on the axial and the appendicular skeleton. J Clin Invest 1982;69:1302-1309.

50. Maes M, Scharpe S, Van Grootel L et al. Higher alpha 1antitrypsin, haptoglobin, ceruloplasmin and lower retinol binding protein plasma levels during depression: further evidence for the existence of an inflammatory response during that illness. J Affect Disord 1992;24:183-192.
51. Maes M, Scharpe S, Meltzer HY et al. Relationships between interleukin-6 activity, acute phase proteins, and function of the hypothalamic-pituitary-adrenal axis in severe depression. Psychiatry Res 1993;49:11-27.

52. Berk M, Wadee AA, Kuschke RH, O'Neill-Kerr A. Acute phase proteins in major depression. J Psychosom Res 1997;43:529-534.

53. Hornig M, Goodman DB, Kamoun M, Amsterdam JD. Positive and negative acute phase proteins in affective subtypes. J Affect Disord 1998;49:9-18.

54. McAdams C, Leonard BE. Neutrophil and monocyte phagocytosis in depressed patients. Prog Neuropsychopharmacol Biol Psychiatry 1993;17:971-984.

55. KoH JM, KHANG YH, JuNG CH et al. Higher circulating hsCRP levels are associated with lower bone mineral density in healthy pre- and postmenopausal women: evidence for a link between systemic inflammation and osteoporosis. Osteoporos Int 2005;16:1263-1271.

56. Pasco JA, Kotowicz MA, Henry MJ et al. Highsensitivity C-reactive protein and fracture risk in elderly women. JAMA 2006;296:1353-1355.

57. Schett G, Kiechl S, Weger S et al. High-sensitivity Creactive protein and risk of nontraumatic fractures in the Bruneck study. Arch Intern Med 2006;166:2495-2501.

58. Cauley JA, Danielson ME, Boudreau RM et al. Inflammatory markers and incident fracture risk in older men and women: the Health Aging and Body Composition Study. J Bone Miner Res 2007;22:1088-1095.

59. Quinn JM, Gillespie MT. Modulation of osteoclast formation. Biochem Biophys Res Commun 2005;328: 739-745.

60. Tanabe N, Ito-Kato E, Suzuki N et al. IL-1alpha affects mineralized nodule formation by rat osteoblasts. Life Sci 2004; 75:2317-2327.

61. Lau FC, Shukitt-Hale B, Joseph JA. Nutritional intervention in brain aging: reducing the effects of inflammation and oxidative stress. Subcell Biochem 2007;42: 299-318.

62. Peake JM, Suzuki K, Coombes JS. The influence of antioxidant supplementation on markers of inflammation and the relationship to oxidative stress after exercise. $\mathbf{J}$ Nutr Biochem 2007;18:357-371.

63. Joseph JA, Shukitt-Hale B, Casadesus G, Fisher D. Oxidative stress and inflammation in brain aging: nutritional considerations. Neurochem Res 2005;30:927-935. 